\title{
Professor Sajid Usman Kaul
}

\author{
(8th March 1941-15th March 2009)
}

\author{
Liaqat Ali ${ }^{1}$, Arshad Taqi ${ }^{2}$ \\ 1. Associate Professor, Department of Anesthesiology \& Pain Medicine, Allama Ibal Medical College / Jinnah Hospital, Lahore, \\ Pakistan; E-mail: aliliaqatdoc@gmail.com; Phone: + 923214364449 \\ 2. Consultant Anesthetist, Kaul Associates (Pvt) Ltd., Lahore, Pakistan; Phone: +92 3214697815
}

Prof. Sajid Usman Kaul touched many lives during his lifetime, significant among them a group of anesthetists he recruited, nurtured, and empowered to take over when he passed the baton. Prof. Kaul became the pioneer of corporate anesthesia and pain services in Pakistan when he established Kaul Associates (Pvt) Ltd.

After his early schooling in Rang Mahal School, college education in Forman Christian College, and graduation from the famous King Edward Medical College Lahore, Dr. Kaul proceeded to the UK in 1965 to earn his FFRCA and to work with some of the biggest names in the profession, including Prof. William W. Mushin, Dr. D. C. White and Prof. John F. Nunn.

Prof. John F Nunn, recognizing his natural ability to get the best out of people he worked with, wrote the following lines about this "pleasant personality".

"[Dr Kaul] has distinguished himself in several ways. Firstly, he has shown a most unusual interest in research. On his own initiative he has arranged four research projects, some in collaboration and others essentially working on his own. Two of these have

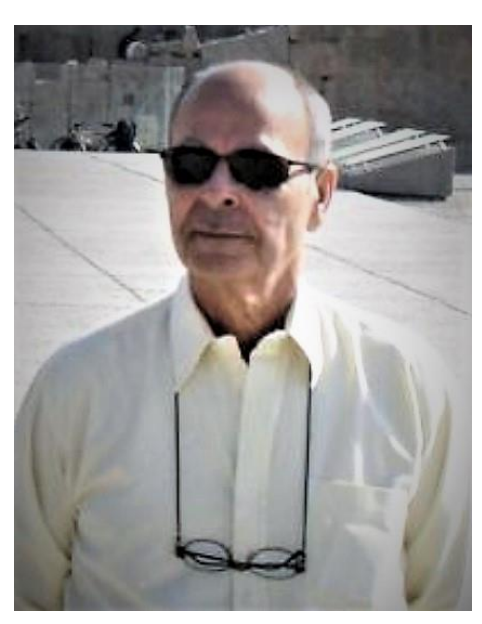

Lahore. He mentored two young aspiring anesthetists, Shahida Khawaja and Tayyab Qureshi, who adopted his ways and championed them among others of their generation. This relationship was the beginning of a new culture in anesthesia with emphasis on preoperative been brought to fruition during nine months working with us and are presently being drafted into excellent papers. The remaining two projects are not yet complete but are progressing well. Secondly, he has shown good organizational ability and has successfully borne the brunt of the day-to-day running of our service. Thirdly, he has integrated into the English way of life to a remarkable extent being now more English than the English; I think this indicates a high degree of adaptability to his environment".

After his father's death, Dr Kaul decided to end a promising career in the UK, returning to live with his mother. He started his career as an assistant professor of anesthesia at King Edward Medical College, Lahore in 1973. He was promoted to Associate Professor in 1977, and posted as head of the department of anesthesia at Allama Iqbal Medical College / Services Hospital, preparation, routine monitoring, and meticulous record keeping.

At the heart of all this was the concept of patient safety. Those inspired by his training conducted formal preoperative assessments, documented each anesthetic used in a notebook they carried and took ownership of the patient throughout their stay in the hospital.

He was promoted to Professor and posted to Nishtar Hospital Multan in 1979. At this point, his conflict with the healthcare establishment intensified. As a consequence he tendered his resignation.

The concept of private healthcare was only just emerging, with limited opportunities for work that could sustain a reasonable lifestyle. A lesser person would have taken the next flight back to the UK. Dr. Kaul did not; he elected to stay in Lahore and work in the private sector.

Private practice, for an anesthetist, meant being on-call all day, running from one private hospital to another, at the mercy of the surgeons and the management of the hospital. Dr. Kaul elected to work within his own schedule and with surgeons who appreciated his skills in providing quality anesthesia care. Remarkably, he did not let the shift from the government sector to the private sector compromise his commitment to lifelong learning and dissemination of knowledge. The Pakistan Society of Anaesthesiologists (PSA) Lahore, provided 


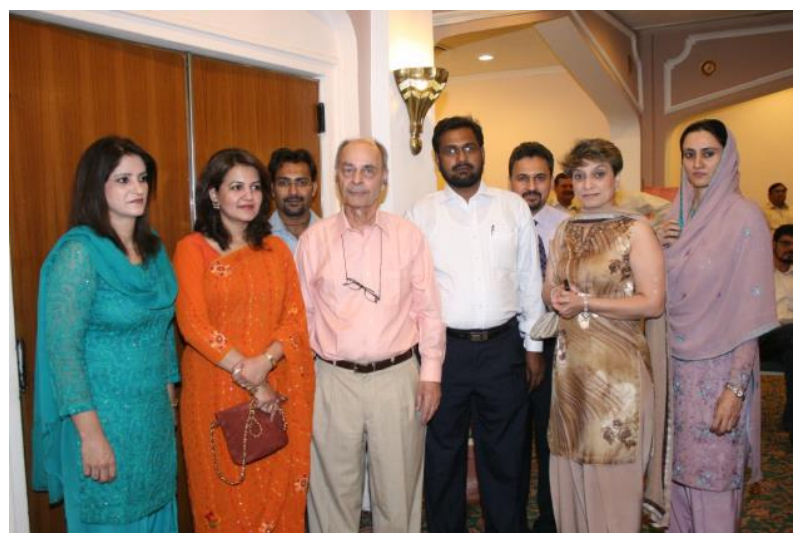

Figure 1: (L to R) Dr. Tahira, Dr. Shamila, Dr. Suhail Anjum, Prof. SU Kaul, Dr. Liaqat Ali, Dr, Jodat Saleem, Prof. Shahida Khawaja, Dr. Asiya Taqi

the platform for him to reach out to those searching for excellence in anesthesia.

Anesthesia was an emerging specialty requiring role models to attract enthusiastic, fresh graduates. In Dr Kaul, it found a person who was proud of being an anesthetist, who commanded fellow professionals' respect, who was willing to dedicate time to teaching, but who was also able to balance this with other interests like playing golf and writing on social issues (he wrote a column for the English newspaper, Frontier Post). A perfect team player, he worked with the likes of Prof. Rustam Nabi, Prof. Attiya Sakhi, and Dr. Razia Asghar to organize scientific and social activities that introduced anesthesia to the healthcare establishment and general public. He was the force behind the first international anesthesia conference organized by PSA Lahore in 1986; the faculty of the meeting included some of the best known experts in anesthesia and inspired several young doctors to choose anesthesia as their specialty and take over the mantle of leadership in the future.

PSA Lahore was among the most dynamic professional societies; it held a regular monthly meeting attended by faculty members and junior doctors. The society secured funds from the Govt. of Punjab in 1986 to establish its head office on Jail Road. Here, PSA Lahore held biannual elections to elect its office bearers. Dr Kaul was elected president the same year and went on to serve two terms. Soon, the PSA Lahore conference became an annual international event.

At one of these conferences, Dr. Kaul shared his vision of setting up a simulation center for teaching anesthesia skills; the Chief Minister of Punjab ordered the project to be set up at Allama Iqbal Medical College Lahore, under the leadership of Prof. Shahida Khawaja. Unfortunately, the project, aimed at establishing standardized teaching in public sector hospitals, was not realized due to bureaucratic hurdles.

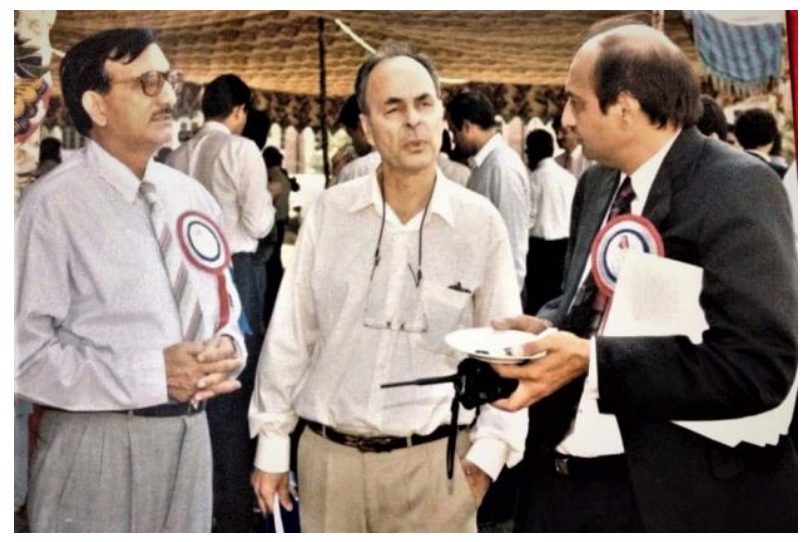

Figure 2: Prof. SU Kaul with Brig M. Salim and Prof. Mahdi Hasan Mumtaz

The Anesthesia Study Group (ASG) was an initiative for the dissemination of knowledge to anesthesiologists. Beginning as an informal teaching session for FCPS Part 2 candidates, it evolved into a platform to manage educational symposia and formal teaching sessions. ASG, in cooperation with the Pakistan Society of Obstetricians and Gynecologists, organized the first symposium on "Obstetrics and Anesthesia" in 1996. Symposia on "Cardiology and Anesthesia" and "Trauma and Anesthesia" followed in collaboration with the respective societies and were followed by more that covered different aspects of anesthesia care. These symposia paved the way to shift the focus of teaching from factual recall of textbooks to evidence-based practice.

Under the patronage of Dr. Kaul, Dr. Khalid Bashir formalised the preparatory courses for fellowship in anesthesiology into a formal two-week course that runs to this day, organized by the next generation of Kaul Associates.

Many young enthusiasts, whom Dr. Kaul inspired to join anesthesia, elected to work with him in his private practice at Rehman Clinic and later on at Omar Hospital; others would join his informal teaching sessions over the weekends at his home in Samanabad. These sessions did not involve didactic teaching; he challenged the participants to explore by asking them questions, identifying their misconceptions, and correcting them. They always left a session wanting more.

Postgraduate Medical Institute Lahore sought Dr. Kaul's help to improve the standards of its postgraduate training and appointed him as honorary professor in 1992. In early 1993, College of Physicians \& Surgeons Pakistan (CPSP) faced problem finding qualified trainers at Lahore, so the CPSP council asked Dr. Kaul to supervise residents training for fellowship in public sector institutions in Lahore. He agreed, and this was the beginning of a new chapter in his life. In 1997 he was 
joined by the first group of residents to train with him at his workplace; inspection and recognition of the department of anesthesia at Hameed Latif Hospital for FCPS Anesthesiology training followed in 2004. This department has produced more than 67 fellows till this day.

Dr. Kaul always strived to identify young enthusiastic anesthesiologists and guide them to assume pioneering roles in niche areas of practice. For example, recognizing her passion for helping women in labor, he encouraged Dr. Shahida Khawaja to start an epidural service in 1986. Likewise, in 1991 he persuaded Dr. Khalid Bashir to train in a pain clinic and start the first pain management service at Lahore.

Dr. Kaul had a keen interest in systemic inquiry and encouraged the people he mentored to conduct research. 1-3 He collaborated with Dr. Mohammad Nasir, the inventor of I-Gel, and led his department in gathering preliminary data on the clinical use of I-Gel.

Like all great journeys, the journey of Kaul Associates began with a small step in 1991. Dr. Kaul, Dr. Shahida Khawaja and Dr. Khalid Bashir formed a team to provide anesthesia cover for infertility service provided by Dr. Rashid Latif and his colleagues. They continued this partnership to provide anesthesia services when Hameed Latif Hospital became operational in 1994. The group posted trained anesthesia doctors to ensure continuity of care for their patients in the postoperative period that was the beginning of an organized perioperative services in the private sector in Lahore. The team introduced many other firsts, including the first 'painless labor service' managed by anesthetists, 'rapid response teams' to care critically ill patients outside critical care areas, 'ultrasound-guided vascular access' and 'anesthesia outside the OR', including 'dental chair sedation'.

The specialty of anesthesia is indebted to a generation of teachers who toiled and persevered to establish its rightful position in healthcare. The PSA published a tribute to Dr Kaul's contributions on its website. 4 Journal of Anesthesiology and Clinical Pharmacology also published his obituary to acknowledge his contribution. ${ }^{5}$ One characteristic, which made him stand out amongst others, was that he wanted his students to become better doctors than he was, and he was always happy to provide them with an opportunity to make this happen.

\section{References}

1. Kaul SU, Beard DJ, Millar RA. Preganglionic sympathetic activity and baroreceptor responses during hypothermia. $\mathrm{Br} \mathrm{J}$ Anaesth. 1973;45:433-9. [PubMed] DOI: 10.1093/bja/45.5.433

2. Kaul SU, HeATH JR, NunN JF. Factors influencing the development of expiratory muscle activity during anaesthesia. $\mathrm{Br} J$ Anaesth. 1973;45(10):1013-1018. [PubMed] DOI: 10.1093/bja/45.10.1013

3. Ali A. Sheikh NA, Khawaja S, Saleem J, Kaul SU. Comparison of intubating conditions produced by rocuronium and suxamethonium for rapid sequence induction in elective caesarean. Annals King Edward Uni.2008;14(1):05. [PubMed] DOI: 10.21649/akemu.v14i1.100

4. Legends of PSA. Prof. Sajid Usman Kaul. Available at https://psacentre.org/our-legends/legends-of-psa/prof-sajidusman-kaul/

5. Taqi A. Obituary. Dr Sajid Usman Kaul. J Anaesthesiol Clin Pharmacol Apr-Jun 2009;25(2):25. [FreeFullText] 